\title{
CORS Usage for GPS Survey in the Greater Accra Region: Advantages, Limitation, and Suggested Remedies
}

\author{
Sebastian Botsyo ${ }^{1}$ (D) $\cdot$ Bernard Borketey Bortei $^{2} \cdot$ John $^{\text {Ayer }}{ }^{3}$
}

Accepted: 4 September 2020 / Published online: 11 September 2020

(C) The Author(s) 2020

\begin{abstract}
The use of Continuously Operating Reference Stations (CORS) enables surveyors to differentially correct static Global Positioning System (GPS) measurements. CORS are designed to support the broad spectrum of post-processed, relative GPS techniques, and applications. Enhancing geospatial positioning applications of CORS data involves the critical role in defining the nation's geodetic reference system. With the establishment of a coordinated system of CORS, an Online Positioning User Service can become available for processing in single positioning mode to provide corresponding accurate and homogeneous positional coordinates. The Survey and Mapping Division (SMD), Lands Commission of Ghana, has established four CORS in the Greater Accra, and Ashanti, Western and Brong-Ahafo Regions, respectively, to provide a basic CORS network in accordance with the International Terrestrial Reference Frame (ITRF). However, most surveyors continue to reference their works in these regions to ground survey beacons that have been coordinated and adjusted by variable survey methods. This obviously makes homogeneity of data unpredictable. This study explored the extent of usage of existing CORS network established by SMD with particular focus on the CORS in the Greater Accra Region for GPS surveys and to determine its usefulness in ensuring homogeneity in GPS data collection. The professional participatory (interviews) technique was coupled with differential GPS field observations with the CORS as reference in one case and ground control stations as reference in the other in making relatively conclusive analysis. Test results showed that GPS field survey of an approximate range of $23 \mathrm{~km}$ away from the Accra CORS yielded an average positional change in Northings and Eastings of $-0.790 \mathrm{~m},-0.176 \mathrm{~m}$ and $-0.681 \mathrm{~m},-0.098 \mathrm{~m}$ for single and dual frequency, respectively, in different localities within the study area. Beyond a range of $25 \mathrm{~km}$ from the Accra CORS, the average positional change in Northings and Eastings are $-0.536 \mathrm{~m},-0.007 \mathrm{~m}$ and $-1.370 \mathrm{~m}, 0.334 \mathrm{~m}$ for single and dual frequency respectively. Of 128 geomatic professionals interviewed, 39\% are aware of the availability of COR stations in Greater Accra, $61 \%$ are unaware, and $28 \%$ are aware and users of the Accra CORS whereas $11 \%$ are aware but non-users of the Accra COR station. Of all users sampled, $17.5 \%$ are regular and frequent users of the Accra COR station and $10.5 \%$ are occasional or seldom users. The results show that the Accra CORS is vital to ensuring a uniform homogenous GPS data. However, very few people are using it due to low public awareness of the usefulness of the CORS among professional surveyors and other users and a cumbersome, bureaucratic nature in CORS data acquisition for post-processing and RTK GPS surveys.
\end{abstract}

Keywords Continuously Operating Reference Stations (CORS) · Homogeneity · International Terrestrial Reference Frame (ITRF) $\cdot$ Beacons $\cdot$ Professional surveyors

Sebastian Botsyo

kwasisesebot@gmail.com

Bernard Borketey Bortei

bengazhi@gmail.com

John Ayer

johnnyayer@gmail.com
Survey and Mapping Division, Lands Commission, Accra, Ghana

2 Real Estate and Security Department, Volta River Authority, Akosombo, Ghana

3 College of Engineering, Geomatic Engineering Department, Kwame Nkrumah University of Science and Technology, Kumasi, Ghana 


\section{Introduction}

GPS usage started in Ghana in the early 1990s particularly for surveying and mapping purposes. The Survey Department of Ghana had prior to this time established nationwide control networks as its geodetic framework for classical surveying using triangulation in the southern parts of the country and precise traversing in the northing sectors. However, these controls were established and adjusted to support survey methods that were available at the time due to available equipment. For example, visible lines of sight or inter-visibility between beacons was one of the considerations in the siting of beacons. Computation and adjustments were also made to derive coordinates based on a Ghana local ellipsoid. One shortfall noticed at the time was that, because of the different methods used in establishing the coordinates (triangulation and traversing) and the fact that each triangulation or traverse net were adjusted separately, the homogeneity of the framework as a whole could not be guaranteed (Ayer et al., 2008).

Though the established network has served useful purposes hitherto, it may no longer satisfy all of modern mapping needs which may include compatibility with the current satellite positioning techniques, using GNSS equipment which is presently widely adopted for almost all mapping and homogeneous cross border mapping activities (Blick et al., 2006; Kotzev, 2013).

The use of the GPS eliminates the necessity of lines of sight which was very important for classical surveying methods. With the GPS measurements, differential positioning is the measurement technique accepted by the Survey and Mapping Division for cadastral purposes. This method results in improved accuracy of positioning by comparing measurements taken by two or more receivers such that one of the receivers called the base is fixed over a control point and the others called rovers are taken to other points. In this way, the difference between the base station's actual location and its calculated location is a measure of the positioning error affecting that receiver at that location and is hence the correction needed to eliminate errors from GPS signals applied to the position calculated by the mobile receiver at the same instant.

The use of CORS enables differential correction to static GPS measurements acquired by referring to the base stations (CORS) collected signals at the same time to perform postprocessing relative to Global Positioning System (GPS) techniques and applications. In addition to this, the CORS has the critical role of defining the nation's geodetic reference system. An established coordinated system of CORS would later help in an Online Positioning User Service for processing in single positioning mode to provide corresponding accurate and homogeneous positional coordinates.

The Survey and Mapping Division (SMD) of Ghana has established four CORS in the Greater Accra, Ashanti, and two in the Western Regions, respectively, to provide a basic
CORS network in accordance with the International Terrestrial Reference Frame (ITRF).

These CORS include the one situated at the Photogrammetric section of SMD in 37, Accra. The established COR stations can accommodate static GPS survey within a distance of about $100 \mathrm{~km}$ and about $20 \mathrm{~km}$ for realtime kinematic (RTK) survey away from each COR station.

\section{Research Problem}

Ghana's control network is bedeviled with the issue of nonclosure of survey works on some controls in certain parts of the country due to varying methods used in establishing them as part of the control network of the country. This poses great threat to geospatial data in Ghana which may produce overlaps leading to litigations and uncertainties. To ensure homogeneity in surveys may require the establishment of new refined controls that are homogeneously adjusted. The current use of GPS for most surveys has provided the impetus for developing a new homogeneous three-dimensional framework that will support differential GPS surveys in Ghana. The established CORS can aid as a starting point to obtaining a country-wide homogeneous framework for all surveys in Ghana. Invariably, even though a few of such CORS are in existence, their awareness is considerably low among potential users making patronage and exploitation very low. In this research, we seek to investigate the merits and limitations of the system and suggest remedies to factors mitigating against the use of the Accra CORS.

\section{Research Aim and Objectives}

The main aim of the project is to explore the use of CORS for GPS survey in Greater Accra.

- Specific objectives include:

- To identify the advantages of CORS for GPS survey

- To investigate the limitations of CORS for GPS survey

- To suggest solutions/remedies of problems in CORS usage for GPS survey

\section{Materials and Methods}

\section{Study Area}

The study area is limited to a $25 \mathrm{~km}$ radius around the Accra CORS station in the Greater Accra Region. The Greater Accra Region of Ghana (Fig. 1) is the smallest of all the ten administrative regions in the country. It is situated in the southcentral part of Ghana and lies between latitudes $5^{\circ} 30^{\prime}$ North 


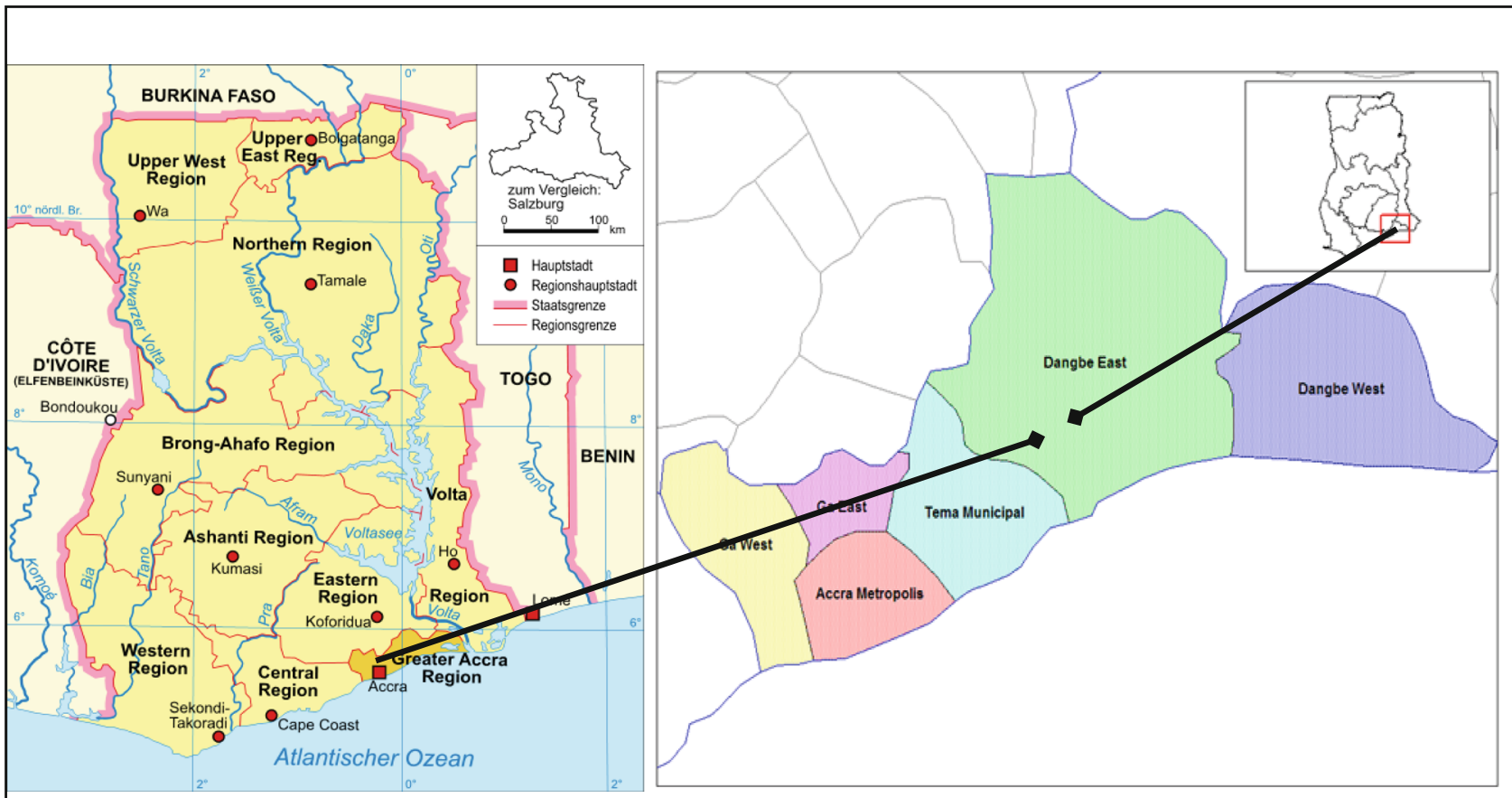

Fig. 1 Study area (Greater Accra Region)

and $6^{\circ} 03^{\prime}$ North and longitudes $0^{\circ} 30^{\prime}$ West and $0^{\circ} 35^{\prime}$ East. It shares borders with the Eastern Region to the north, the Volta Region to the east, on the south by the Gulf of Guinea, and the Central Region to the west. It has a coastline stretching from Kokrobite in the west to Ada in the east. The region covers an area of about 3245 square $\mathrm{km}$. It is the second most populated region, after the Ashanti Region, with a population of almost 3 million. The Greater Accra Region currently harbors the seat of government in Accra.

The region is predominantly a low-lying undulating coastal plain with heights scarcely reaching more than $76.2 \mathrm{~m}$ above sea level, except where the topography is broken by hills. In the northeastern part of the region are the Shai Hills which rise to about $304.8 \mathrm{~m}$. On the western end are the rounded low hills of between 121.92 and $152.4 \mathrm{~m}$ found on the Togo series and the Cape Coast formations. A section of the Akwapim Ranges intrudes into the eastern half of the region with heights rising to about $213.36 \mathrm{~m}$..

The vegetation of the region is of the coastal savanna grassland type, but occurring here and there within the savanna are thickets of forests along the stream courses and mangrove and swampy vegetation along the coastal lagoons. Along the piedmont of the Akwapim Ranges at the northwestern section of the region can be found a gallery of forests and remnants of high forest vegetation.

The location of Accra and Tema in the region has made the Greater Accra the industrial center of the country. The region boasts of more than 200 major manufacturing industrial establishments which include an oil refinery mostly located in Accra and Tema. For this reason, the region consumes about
$46.5 \%$ out of the total electricity generated in the whole country. Accra and Tema are also the largest market area for the country's manufactured products.

\section{Materials Used}

Materials used in this study include:

i. The Accra CORS used as reference for field GPS survey

ii. Geodetic GPS receivers and processing software

iii. GPS field observations

iv. Structures questionnaires and interviews.

v. AutoCAD and ArcGIS for drawing and analyzing results

\section{Methodology}

In this research, the use of questionnaires was deployed in conjunction with field observation (GPS observation using the CORS as the base station). A purposive sampling technique was used in questionnaire administration, and feedback and vital information from the questionnaires were obtained and analyzed. The methodological steps are described in Fig. 2 and below.

\section{Questionnaires}

The questionnaires were tailored towards getting enough information about the use of the Accra CORS established by the Survey Department of Ghana situated in 37 Military Hospital. 
Fig. 2 Methodology flowchart

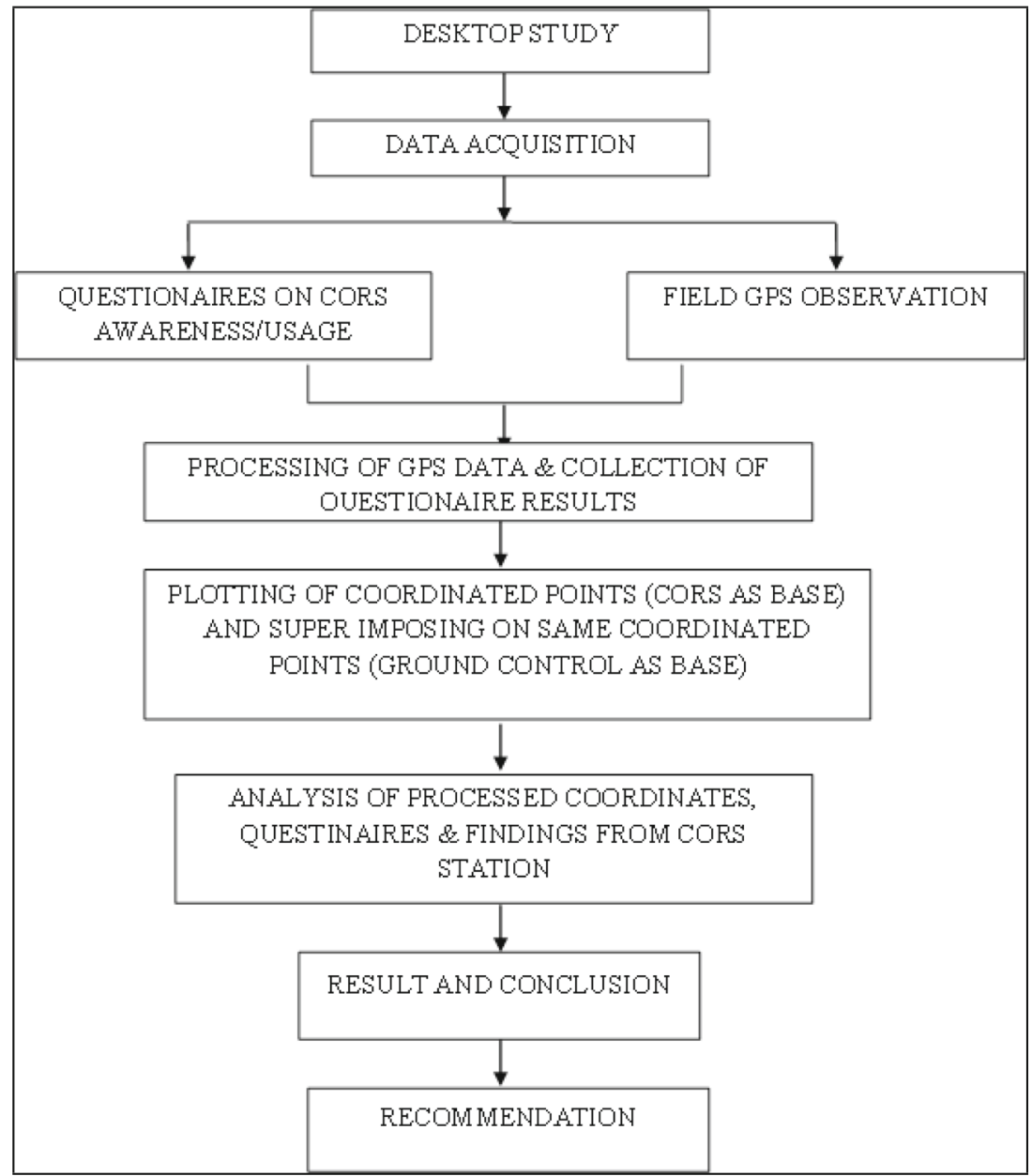

As such, the target groups were geospatial data collectors. Therefore, a purposive sampling approach was used in addition to structured questionnaire. The head of the GRN section and a staff were also interviewed.

\section{Field GPS Observation}

The field observation was performed based on the approved and frequently used differential positioning technique in Ghana. This technique was undertaken in post-processing mode. GPS data were acquired from different locations in Accra that are well within the CORS range. This range encompasses areas for which survey works are mostly done for cadastral plans preparation for title registration.

This is to test the results of processed GPS data using the CORS as reference station against the results obtained from processed GPS data using other ground controls as reference which, in actual fact, is still accepted by the Survey Department of Ghana. Most of these GPS survey works were carried with different survey instruments such as the Sokkia Stratus single-frequency GPS, Ashtech Locus singlefrequency GPS, and the Topcon dual-frequency GPS.
After field data was acquired, a formal request was sent to the Accra GRN station on the 12th day of April 2016 for the reference data needed to process the field data on specific field observation dates. It is noteworthy that the CORS data was granted on 25 April 2016 which is 13 clear days after the request was placed.

\section{Data Processing}

Post-processing was carried in two instances. The first was processing of the field data with the specific GPS brand of software where the ground control was used as reference in which the results were used to prepare cadastral plans. The second processing was processing of the field data with the GNSS 3.80 software where the COR station was used as reference. For compatibility reasons, the GPS field data was converted into Receiver Independent Exchange Format (RINEX) which is a data interchange format for raw satellite navigation system data using tools in the specific brand of GPS software so as to have all data in the same format for processing with single GNSS software. 
Table 1 GPS field observation controls information

\begin{tabular}{|c|c|c|c|}
\hline Location (date) & GPS instrument & Software & Ground reference \\
\hline Domiabra (24 March 2016) & Ashtech Locus single frequency & Ashtech solutions 2.60 & $\begin{array}{l}\text { SGGA } 905983 \\
\text { N: } 97658.828 \\
\text { E: } 347151.966\end{array}$ \\
\hline Ablekuma and Obakrowa (25 March 2016) & Ashtech Locus single frequency & Ashtech solutions 2.60 & $\begin{array}{l}\text { SGGA } 791724 \\
\text { N: } 105801.898 \\
\text { E: } 353441.109\end{array}$ \\
\hline Achiaman (28 March 2016) & Topcon hyper lite plus dual frequency & Topcon Tools 8.2.3 & $\begin{array}{l}\text { SGGA J799 } 144 \\
\text { N: } 114169.568 \\
\text { E: } 352053.276\end{array}$ \\
\hline Bortianor (29 March 2016) & Sokkia Stratus single frequency & Spectrum survey 3.22 & $\begin{array}{l}\text { SGGA } 905983 \\
\text { N: } 97658.828 \\
\text { E: } 347151.966\end{array}$ \\
\hline Doblo Gonno (30 March 2016) & Topcon hyper lite plus dual frequency & Topcon Tools 8.2.3 & $\begin{array}{l}\text { SGGA J799 } 144 \\
\text { N: } 114169.568 \\
\text { E: } 352053.276\end{array}$ \\
\hline
\end{tabular}

\section{Plotting}

The post-processed coordinates of the various GPS field observations were plotted for a graphical appreciation and analysis. AutoCAD 2010 was used to plot the coordinates that were post-processed from both ground control as reference in one case and the CORS as reference in the second case. ArcGIS 10.2 was also used to add a more graphical touch to the AutoCAD drawing and for analysis. The results of the plotting are shown in "Results and Analysis" section.

\section{Results and Analysis}

The focus here is on the positional reliability of the Accra CORS data for post-processing a differential GPS survey in the Greater Accra Region of Ghana. This analysis is done relative to field GPS data for post-processing differential GPS survey in the Greater Accra where controls are used as references. The questionnaires are also analyzed to determine the usage of the CORS.

\section{Field GPS Data Processing (Ground Control Reference)}

The reference coordinates used for the various survey works are based on the Ghana Grid system, and all coordinates are meters as shown in Table 1.

\section{Positional Differences In Processed Coordinates By The Differing Bases}

The differences in the coordinates obtained through the use of CORS data for differential GPS positioning as against using other ground controls in meters are shown in Table 2.

\section{Composite Plans of Results}

Figure 3 and Fig. 4 show composite plans from results obtained using CORS and other ground controls within distances less than $25 \mathrm{~km}$ from the CORS.

From the results of observations taken, approximately $23 \mathrm{~km}$ away from the Accra COR station, results showed that an average of $-0.715 \mathrm{~m}$ change in Northings and $-0.075 \mathrm{~m}$ change in Eastings for Bortianor with a Sokkia Stratus singlefrequency GPS with an occupation time of $20 \mathrm{~min}$. Likewise an average of $-0.681 \mathrm{~m}$ change in Northings and $-0.098 \mathrm{~m}$ change in Eastings was obtained for Achiaman using the Topcon hyper plus dual-frequency GPS with an occupation time of $4 \mathrm{~min}$. Comparatively, both Northings and Eastings show a remarkable similarity in change in Northings and a slight difference in the change in Eastings. The changes are relatively minimal and acceptable for preparation of cadastral plans in conformity with the standards of GPS surveys in Ghana as stipulated by the Technical Guidelines of Survey in Ghana. This gives room to say that even with an increased occupation/observation time within such a range away from the Accra COR station, more accurate results are bound to be achieved making the Accra COR station very good to use for GPS survey works in cadastral plan preparation and other GPS survey related works over such a distance.

Figures 5 and 6 show composite plans for distances at approximately $25 \mathrm{~km}$ from the Accra CORS.

From the results obtained at approximately $25 \mathrm{~km}$ away from the Accra COR station, an average of $-0.536 \mathrm{~m}$ change in Northings and $-0.007 \mathrm{~m}$ change in Eastings was obtained for Domiabra and Ablekuma and Obakrowa with a Ashtech Locus single-frequency GPS with an occupation time of $25 \mathrm{~min}$. Likewise, an average of $-1.370 \mathrm{~m}$ change in 
Table 2 Positional differences in coordinates

\begin{tabular}{|c|c|c|c|c|c|c|}
\hline \multirow[t]{2}{*}{ Point ID (instrument type) } & \multicolumn{2}{|c|}{ Processed field data (ground control as base) } & \multicolumn{2}{|c|}{$\begin{array}{l}\text { Processed field data } \\
\text { (CORS as base) }\end{array}$} & \multicolumn{2}{|c|}{ Positional differences } \\
\hline & Northings (Xm) & Eastings (Ym) & Northings $(\mathrm{Xm})$ & Eastings (Ym) & $\Delta \mathrm{X}$ & $\Delta \mathrm{Y}$ \\
\hline Accra GRN (CORS) & & & $101,917.657$ & $364,850.848$ & & \\
\hline Ashtech Locus single frequency & $24.283 \mathrm{~km}$ from CORS & Domiabra & & & & \\
\hline AA1 & $103,944.372$ & $340,654.039$ & $103,944.885$ & $340,656.976$ & 0.514 & 2.937 \\
\hline $\mathrm{AA} 2$ & $103,945.513$ & $340,623.734$ & $103,945.947$ & $340,626.624$ & 0.434 & 2.890 \\
\hline AA3 & $103,965.951$ & $340,624.065$ & $103,964.765$ & $340,623.781$ & -1.186 & -0.283 \\
\hline \multirow[t]{3}{*}{ AA4 } & $103,966.075$ & $340,654.684$ & $103,964.889$ & $340,654.401$ & -1.187 & -0.283 \\
\hline & & & & Average & -0.356 & 1.315 \\
\hline & $25.064 \mathrm{~km}$ from CORS & Domiabra & & & & \\
\hline BB1 & $104,468.219$ & $339,917.460$ & $104,467.033$ & $339,917.187$ & -1.186 & -0.273 \\
\hline BB2 & $104,452.000$ & $339,916.076$ & $104,450.813$ & $339,915.803$ & -1.187 & -0.273 \\
\hline BB3 & $104,474.706$ & $339,844.402$ & $104,473.517$ & $339,844.130$ & -1.188 & -0.272 \\
\hline BB4 & $104,511.518$ & $339,859.879$ & $104,510.330$ & $339,859.606$ & -1.188 & -0.273 \\
\hline BB5 & $104,498.164$ & $339,896.732$ & $104,495.470$ & $339,896.384$ & -2.694 & -0.347 \\
\hline \multirow[t]{3}{*}{ BB6 } & $104,478.635$ & $339,888.689$ & $104,475.942$ & $339,888.343$ & -2.693 & -0.346 \\
\hline & & & & Average & -1.689 & -0.298 \\
\hline & $24.523 \mathrm{~km}$ from CORS & Domiabra & & & & \\
\hline $\mathrm{CC} 1$ & $104,908.995$ & $340,481.371$ & $104,907.827$ & $340,481.114$ & -1.168 & -0.257 \\
\hline $\mathrm{CC} 2$ & $104,900.921$ & $340,510.325$ & $104,899.753$ & $340,510.067$ & -1.169 & -0.258 \\
\hline $\mathrm{CC} 3$ & $104,877.361$ & $340,499.521$ & $104,876.036$ & $340,499.065$ & -1.325 & -0.455 \\
\hline \multirow[t]{3}{*}{$\mathrm{CC} 4$} & $104,892.137$ & $340,472.371$ & $104,890.823$ & $340,472.247$ & -1.315 & -0.124 \\
\hline & & & & Average & -1.244 & -0.274 \\
\hline & $22.887 \mathrm{~km}$ from CORS & Domiabra & & & & \\
\hline DD1 & $96,001.2165$ & $342,729.289$ & $95,999.57635$ & $342,730.036$ & -1.640 & 0.747 \\
\hline DD2 & $96,012.8205$ & $342,702.670$ & $96,011.17094$ & $342,703.507$ & -1.650 & 0.837 \\
\hline DD3 & $96,033.346$ & $342,708.255$ & $96,031.91411$ & $342,707.840$ & -1.432 & -0.415 \\
\hline \multirow[t]{2}{*}{ DD4 } & $96,020.574$ & $342,736.239$ & $96,019.237$ & $342,735.847$ & -1.337 & -0.392 \\
\hline & & & & Average & -1.515 & 0.194 \\
\hline Ashtech Locus single frequency & $14.989 \mathrm{~km}$ from CORS & Ablekuma and Obakrowa & & & & \\
\hline A1 & $105,624.179$ & $350,294.733$ & $105,624.018$ & $350,293.995$ & -0.161 & -0.738 \\
\hline A2 & $105,645.446$ & $350,296.301$ & $105,645.300$ & $350,295.417$ & -0.146 & -0.884 \\
\hline A3 & $105,642.600$ & $350,330.522$ & $105,642.472$ & $350,330.041$ & -0.128 & -0.481 \\
\hline \multirow[t]{3}{*}{ A4 } & $105,621.328$ & $350,326.962$ & $105,621.200$ & $350,326.483$ & -0.128 & -0.479 \\
\hline & & & & Average & -0.141 & -0.646 \\
\hline & $25.317 \mathrm{~km}$ from CORS & Ablekuma and Obakrowa & & & & \\
\hline B1 & $110,839.099$ & $341,126.818$ & $110,840.229$ & $341,125.945$ & 1.130 & -0.872 \\
\hline B2 & $110,868.741$ & $341,148.286$ & $110,869.900$ & $341,147.616$ & 1.159 & -0.670 \\
\hline B3 & $110,858.996$ & $341,165.778$ & $110,860.155$ & $341,165.109$ & 1.159 & -0.669 \\
\hline \multirow[t]{2}{*}{ B4 } & $110,820.037$ & $341,135.848$ & $110,821.166$ & $341,134.975$ & 1.130 & -0.873 \\
\hline & & & & Average & 1.145 & -0.771 \\
\hline Topcon hyper plus dual frequency & $22.187 \mathrm{~km}$ from CORS & Achiaman & & & & \\
\hline $\mathrm{AB} 1$ & $114,165.839$ & $346,328.294$ & $114,165.205$ & $346,328.276$ & -0.634 & -0.019 \\
\hline $\mathrm{AB} 2$ & $114,153.533$ & $346,309.612$ & $114,153.275$ & $346,309.857$ & -0.258 & 0.245 \\
\hline AB3 & $114,124.179$ & $346,323.631$ & $114,123.678$ & $346,322.535$ & -0.500 & -1.095 \\
\hline AB4 & $114,137.129$ & $346,339.082$ & $114,136.196$ & $346,340.062$ & -0.927 & 0.981 \\
\hline AB5 & $114,148.930$ & $346,358.287$ & $114,147.799$ & $346,357.985$ & -1.131 & -0.302 \\
\hline AB6 & $114,177.261$ & $346,346.681$ & $114,176.628$ & $346,346.280$ & -0.634 & -0.401 \\
\hline
\end{tabular}


Table 2 (continued)

\begin{tabular}{|c|c|c|c|c|c|c|}
\hline \multirow[t]{2}{*}{ Point ID (instrument type) } & \multicolumn{2}{|c|}{ Processed field data (ground control as base) } & \multicolumn{2}{|c|}{$\begin{array}{l}\text { Processed field data } \\
\text { (CORS as base) }\end{array}$} & \multicolumn{2}{|c|}{ Positional differences } \\
\hline & Northings (Xm) & Eastings (Ym) & Northings $(\mathrm{Xm})$ & Eastings (Ym) & $\Delta \mathrm{X}$ & $\Delta \mathrm{Y}$ \\
\hline & & & & Average & -0.681 & -0.098 \\
\hline Sokkia Stratus single frequency & $22.737 \mathrm{~km}$ from CORS & Bortianor & & & & \\
\hline $\mathrm{P} 1$ & $93,598.626$ & $343,690.776$ & $93,597.754$ & $343,690.486$ & -0.872 & -0.290 \\
\hline P2 & $93,561.278$ & $343,671.574$ & $93,560.608$ & $343,671.932$ & -0.671 & 0.358 \\
\hline P3 & $93,574.716$ & $343,645.322$ & $93,574.080$ & $343,645.163$ & -0.636 & -0.159 \\
\hline \multirow[t]{2}{*}{ P4 } & $93,613.053$ & $343,663.030$ & $93,612.374$ & $343,662.821$ & -0.679 & -0.209 \\
\hline & & & & Average & -0.715 & -0.075 \\
\hline Topcon hyper plus dual frequency & $24.948 \mathrm{~km}$ from CORS m & Doblo Gonno & & & & \\
\hline PP1 & $114,113.087$ & $343,061.831$ & $114,111.813$ & $343,062.144$ & -1.274 & 0.314 \\
\hline PP2 & $114,112.81$ & $343,036.226$ & $114,111.350$ & $343,036.463$ & -1.460 & 0.236 \\
\hline PP3 & $114,056.204$ & $343,041.174$ & $114,056.220$ & $343,041.807$ & 0.017 & 0.632 \\
\hline \multirow[t]{2}{*}{ PP4 } & $114,057.531$ & $343,055.273$ & $114,054.769$ & $343,055.428$ & -2.762 & 0.155 \\
\hline & & & & Average & -1.370 & 0.334 \\
\hline
\end{tabular}

The italised values are the main reference controls for the GPS observations

Northings and $0.334 \mathrm{~m}$ change in Eastings was obtained in Doblo Gonno using a Topcon hyper plus dual-frequency GPS with an occupation time of $5 \mathrm{~min}$. Comparatively, both Northings and Eastings show a remarkable similarity in change in Northings and a slight difference in the change in Eastings for both single- and dual-frequency GPS observations. The changes are relatively minimal in the Easting as compared with the change in Northings. This presents the opportunity to mention that even with an increased occupation/observation time within an approximate $25-\mathrm{km}$ range away from the Accra COR station, finer results are bound to be achieved. This makes the Accra COR station very good option for GPS survey works in cadastral plan preparation and other GPS survey related endeavors even over such a distance.

The performances of single- and dual-frequency receivers are illustrated in Figs. 7 and 8.
As shown in the figures, there is a uniform correlation in the various changes in Northings and Eastings from either the single-frequency or dual-frequency perspective with only non-uniformity in the Eastings of the two dual-frequency observations. The changes in Northings, change in Eastings of the single-frequency observation and change in Northings of the dual-frequency observation are negative in nature respectively leaving the change in Eastings of both the single and dual frequency respectively inversely related. This is to confirm that over a range of either 23 or $25 \mathrm{~km}$ away from the Accra CORS, there is a consistent change in the position relative to positions processed using ground controls as base. In as much as these point positions are safe for the preparation of cadastral plans accepted by the Survey Department, the CORS can also be used in that regard as well. Mindfully, the Accra COR station was established with a range of $100 \mathrm{~km}$ for any GPS survey undertaken. Since Accra is not beyond $26 \mathrm{~km}$,
Fig. 3 Single frequency (approximately $23 \mathrm{~km}$ from CORS Bortianor site)

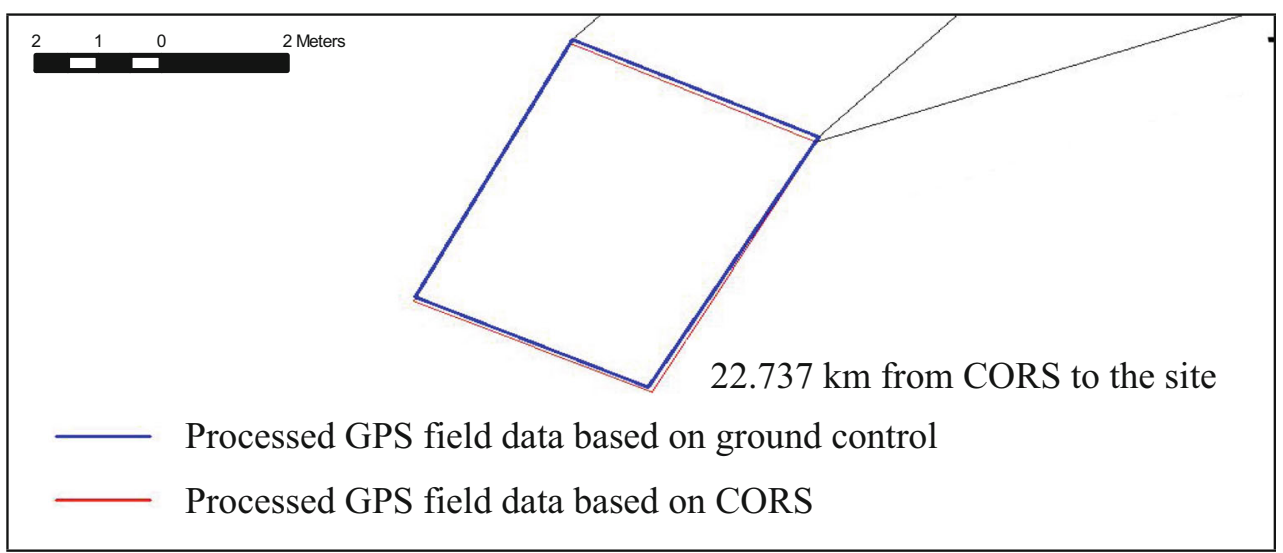


Fig. 4 Dual frequency (approximately $23 \mathrm{~km}$ from CORS to Achiaman site)

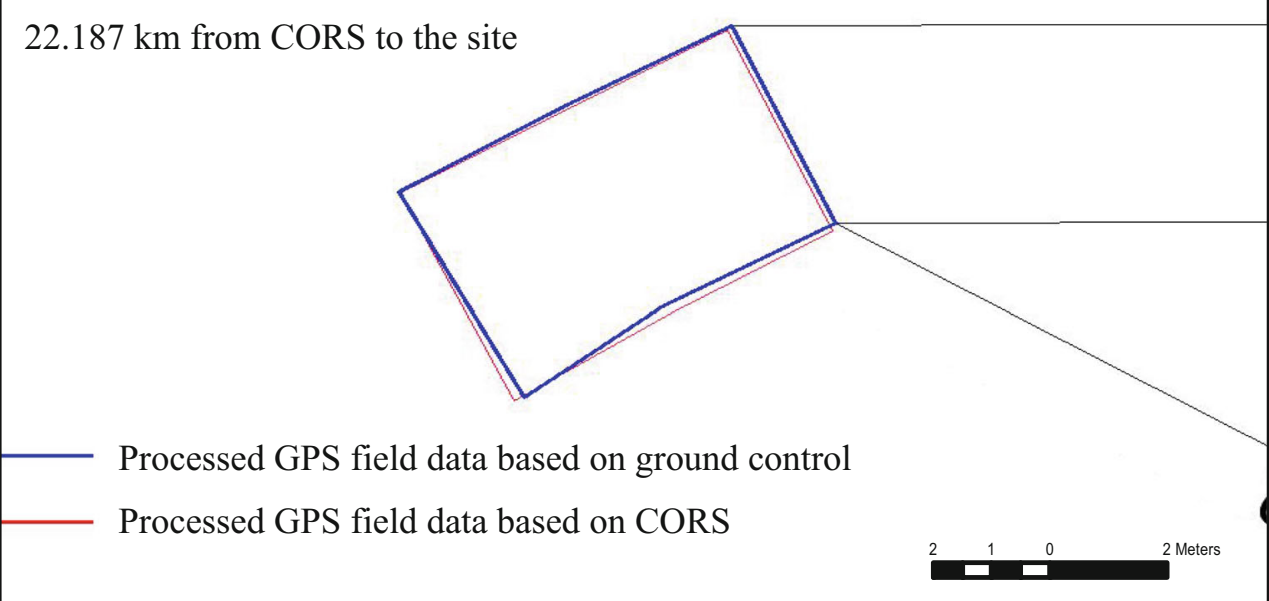

then all GPS survey in Accra can be carried out using the Accra CORS as base. Based on such results, the CORS station can guarantee a system of homogenous and consistent coordinates which the use of the ground controls as base may not guarantee. As GPS usage with respect to ITRF also guarantee plate tectonic movement detection and compensation, in case of any future shifts in coordinate systems, GPS surveys conducted with the COR station as a reference could accommodate and ascertain such shifts which cannot be guaranteed in the case of using the ground controls as base.

According to Ayer et al. (2008), to provide a proper network of framework points as the basis for cadastral surveys throughout the whole country, the nature of the country necessitated the judicious blend of triangulation and traversing. Triangulation was done in the southern areas where there were high mountains and hills that afforded long sights whereas traversing was done in the Northern territories and other low-lying regions. Because of the limitations in computational aids at the time of the original triangulation, the triangulation net was adjusted in smallish figures so that homogeneity or lack of homogeneity for the whole network could not be guaranteed. The primary traverses similarly were very good individually but could be collectively out of alignment.

Therefore, the comparison of GPS observations made with CORS and ground controls as base stations respectively was to show the disparities in the coordinates obtained regardless of all the sources of errors in GPS observations. This is to ensure homogeneity in coordinates if the CORS is used for GPS surveys. A look at the identifiers of the ground controls clearly showed that they were established based on separate traverse with their associated errors. It can be said that these inherent errors in the separate traverses had to some extent effect on the results of the observations using the ground controls without the consideration of the effect of sources of errors in GPS observations since the idea is to indicate that the datum of ground control and CORS are not uniform.
Fig. 5 Single frequency (approximately $25 \mathrm{~km}$ from CORS to Domiabra site)

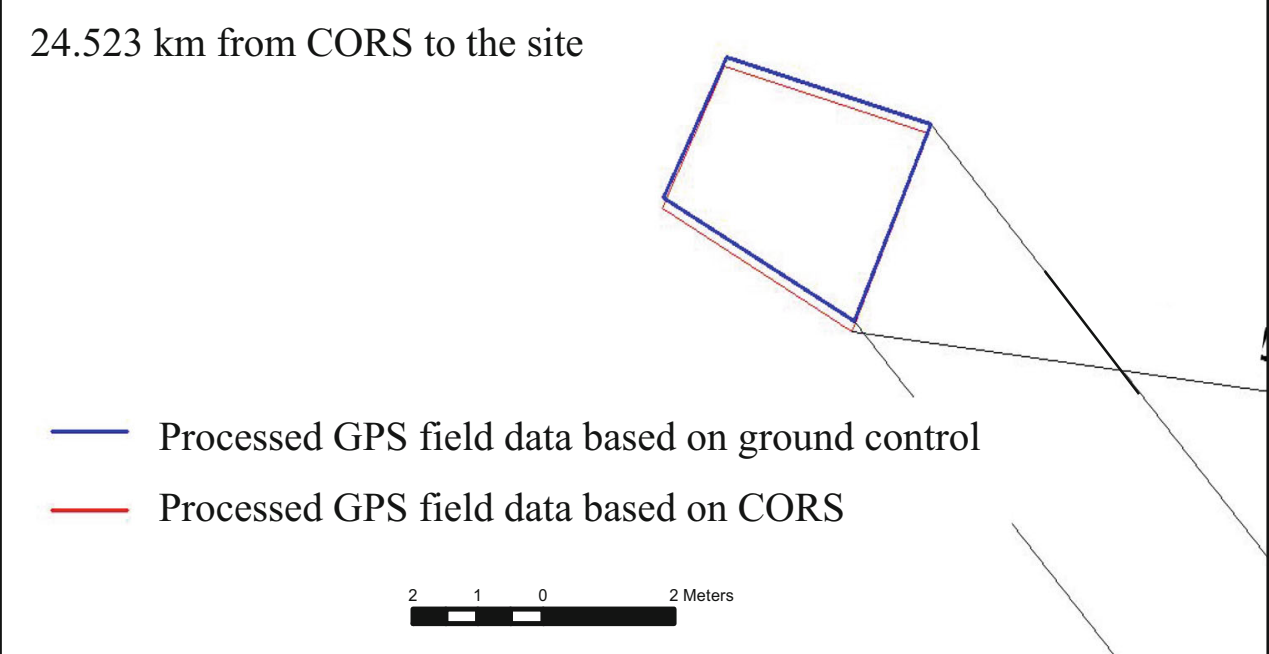


Fig. 6 Dual frequency (approximately $25 \mathrm{~km}$ from CORS, Doblo Gonno site)
$24.948 \mathrm{~km}$ from CORS to the site

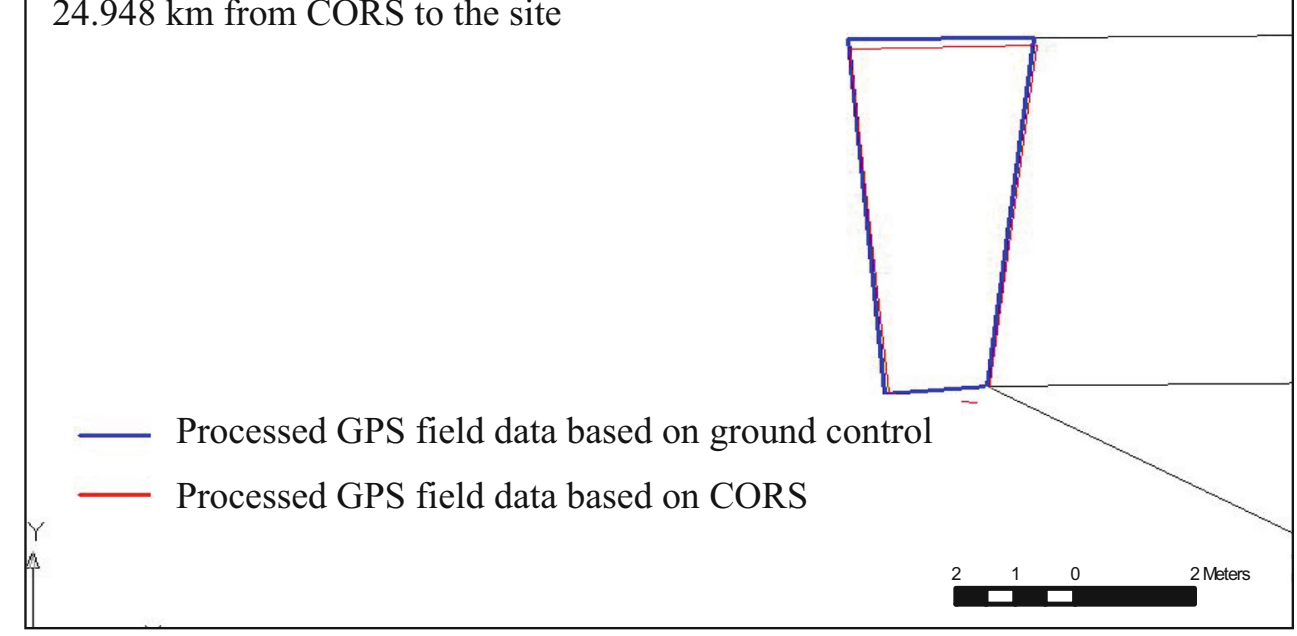

From Table 2, the summation of the averages of change in the Northings and Eastings are $-6.566 \mathrm{~m}$ and $-0.318 \mathrm{~m}$, respectively. This clearly showed that the comparison accuracy of the north direction is higher than that of the east direction due to the different coordinate systems and the separate traverses used to establish the ground controls. Ayer et al. (2008) explained that there are three different coordinate systems in Ghana-Ghana Grid called War Office, "Clarke1880," and WGS84, with the WGS84 as the universal one. Each one of these coordinate systems is used in Ghana, but the differences between them are a result of the different ellipsoids used for their definition. Most of the ground controls in Ghana were established based on War Office, "Clarke1880" coordinate systems. The positional shift between the two different ellipsoidal projected coordinate systems is on the average of $7.620 \mathrm{~m}$ towards the north direction; hence, the $6.566 \mathrm{~m}$ average change in the northing coordinates of the GPS observations is an indication of the presence of that error of shift between the two coordinate systems.

\section{Results From Questionnaires}

A total number of 130 questionnaires were administered out of which 128 were received. The categorization of sampled respondents includes private professional surveyors in the Ghana Institution of Surveyors (GhIS). Figure 9 shows a chart of users and non-users of the Accra CORS from respondents.

The results show that:

- $61 \%$ of professionals are unaware of COR stations availability in the Greater Accra for GPS survey works and other GNSS applications at all.

- $39 \%$ of professionals are aware of COR stations availability in the Greater Accra for GPS survey works and other GNSS applications.

- $28 \%$ of professionals out of $39 \%$ of those who are aware from the collated answered questionnaires have used the COR stations for their GPS surveys.
Fig. 7 Average positional change for single- and dual-frequency observation (23 km from CORS)

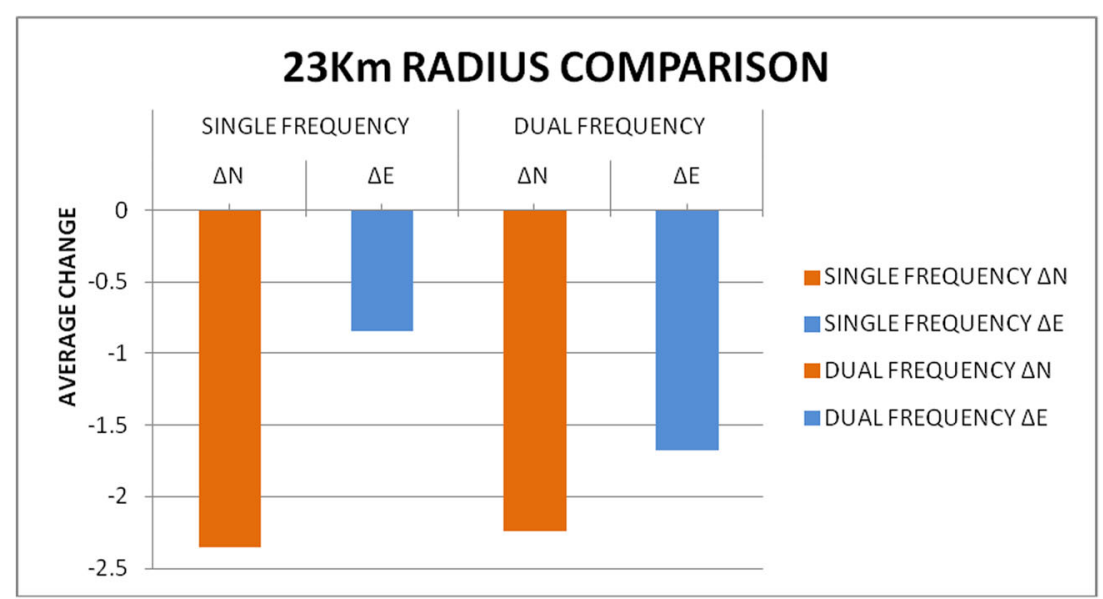


Fig. 8 Average positional change for single- and dual-frequency observation ( $25 \mathrm{~km}$ from CORS)

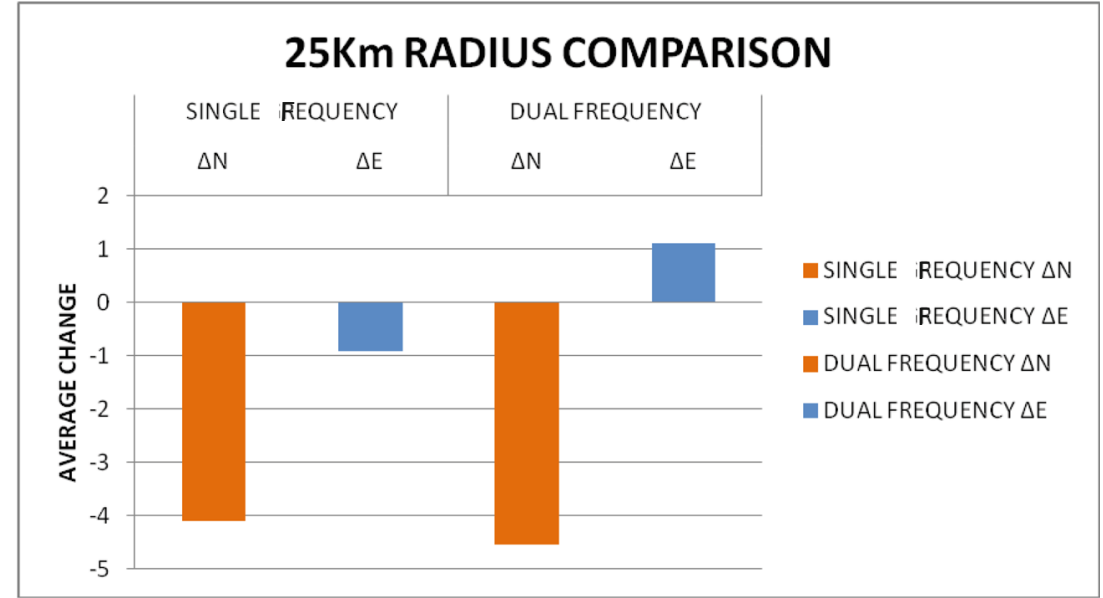

- Similarly, $11 \%$ of these $39 \%$ professionals who are aware of the COR station do not use the CORS for any of their GPS survey works.

Figure 10 is a bar chart showing frequent and occasional users of the CORS.

- Regular/Frequent users of the Accra COR station constitute $17.5 \%$ out the total number of users. These professional surveyors use it to carry out most of their survey works within the allowable threshold of $100 \mathrm{~km}$ further from any CORS within the Greater Accra Region.

- A sizeable $10.5 \%$ of those interviewed seldom uses the Accra GRN or any other COR station in Greater Accra because they are either not aware of the availability of COR or they do not know the functional capability of COR station in their various GPS survey works.

Some of the general comments made by some of these professional surveyors who are either aware or do not use CORS include:
- The lack of adequate and sufficient publicity from the Survey Department about the usefulness of the COR station in GPS surveys.

- The lack of alternate power generating plant for the Accra COR station giving rise to loss of reference data at times when they are most needed.

- The cumbersome, bureaucratic, and time-wasting nature of the managers of the COR station compelling them to give preference to the readily available ground control station for their GPS surveys.

- The unavailability of a quick mechanism of obtaining such reference data without visiting the Survey Department office.

- Some also raised issues of not being abreast with the technological advancement and therefore find it difficult to do the data processing on their own. They, therefore, rely on other professionals to get their GPS survey works processed, and most of the time, these reliant professional are not always available to help them hence the need to resort to the use of ground controls which is relatively faster for data post-processing.
Fig. 9 Users and Non-users of the Accra CORS

\section{CORS USERS \& NON-USERS}

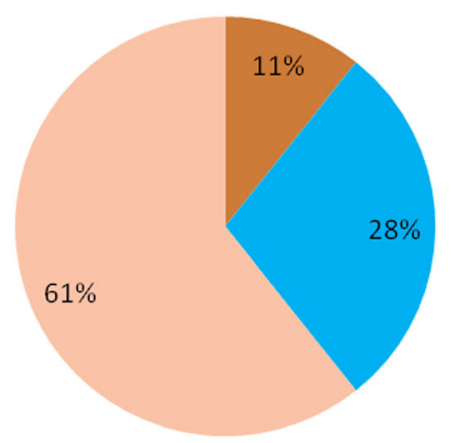

AWARE BUT NOT USERS

- USERS

- UNAWARE 


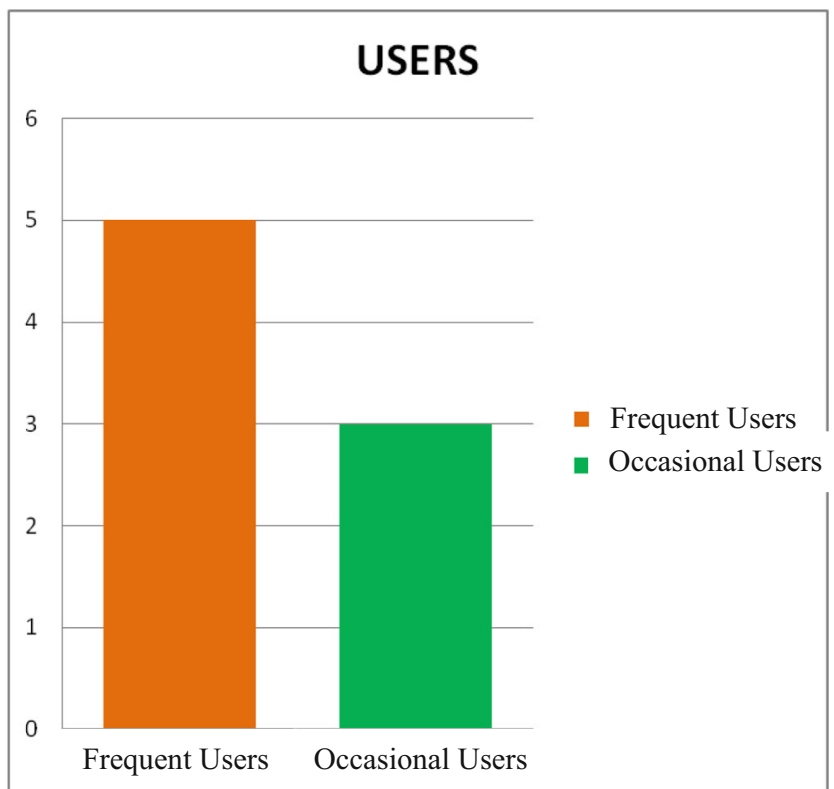

Fig. 10 Users of the Accra CORS

\section{Conclusion and Recommendations}

\section{Conclusions}

The study aimed at exploring the use of CORS for GPS survey and to prove the importance of the CORS usage in providing homogeneity in controls in Greater Accra through participatory/interview analysis coupled with field GPS survey of some parts of the capital city of Accra.

The research questions that this study seeks to uncover in relation to the findings from this research includes:

What are the advantages of CORS usage for GPS survey?

The first obvious answer to this question is the fact that the CORS guarantees a homogeneous differentially corrected coordinates from GPS observations in addition to acting as a control framework. It was also determined that positional differences, though at times minimal, existed between results processed using the CORS and those from existing ground controls for which observations have been made about their non-homogeneity. The results showed changes in the Northings and Eastings for both single and dual frequency as $-0.790 \mathrm{~m},-0.176 \mathrm{~m}$ and $-0.681 \mathrm{~m},-0.098 \mathrm{~m}$, respectively, over an approximate range of $23 \mathrm{~km}$ away from the Accra COR station. It goes further to show that over an approximate distance of over $25 \mathrm{~km}$ away from the Accra COR station, the change in Northings and Eastings of both single- and dualfrequency observations are $-0.536 \mathrm{~m},-0.007 \mathrm{~m}$ and $1.370 \mathrm{~m}, 0.334 \mathrm{~m}$, respectively.

What are the limitations of CORS usage for GPS survey?

The results gathered from the questionnaires raised concerns and limitations about the Accra COR station including:

- The lack of a backup battery system or energy generating system as a stand-by for the Accra COR station. This poses serious limitation in the collection of reference data for post-processing of field data.

- The lack of adequate and sufficient publicity from the Survey Department about the existence, operationality, and usefulness of the COR station for GPS surveys.

- The cumbersome, bureaucratic, and time-wasting nature of the managers of the COR station compelling to give preference to the readily available ground control station for GPS surveys.

- The greater amount of time needed for observation at ranges greater than $12 \mathrm{~km}$ away from the Accra COR station as reported through the questionnaires/interviews from personnel responsible for managing the Accra COR station.

- The unavailability of a ready system of transmitting reference data to users by text or through the Internet.

How can we remedy problems posed by using CORS for GPS survey?

This objective is highly imperative to the success and sustainability of the Accra CORS. Some of the suggestions to remedy problems posed by using the Accra COR station include:

- A shift of focus into giving adequate publicity of the Accra CORS at various levels ranging from the Ghana Survey Department, the Ghana Institution of Surveyors (GhIS), and the Licensed Surveyors Association of Ghana.

- Making the Accra COR station more efficient by mobilizing capital and providing needed resources such as radio receivers and other technological equipment capable of enabling real-time processing of GPS data.

- Setting up a more organized and concrete unit equipped with more expertise that will facilitate a quick response to CORS reference data to drive surveyors to explore its usage in their GPS survey works.

- Mobilizing resources to establish an ultra-modern power generating plant to assist in the reference data recording process in a non-stop fashion to make data available at any time, any day, and everyday.

\section{Recommendations}

The analysis done in this study focused on the Accra COR station. Nevertheless, another study can be done with the focus on other CORS to ascertain if the reasons for non-usage 
are conclusive. To further improve on this research, the reliable use of CORS for coordinating ground controls can also be explored. This is to prove the necessary and reliable status of ground controls coordinated with the CORS for GPS surveys in Ghana.

Acknowledgments We would like to initially express our sincere thanks to the Almighty God for the life, strength, knowledge, and understanding given to us throughout our period of study and a successful completion of this project. We also express our profound gratitude to Rev. John Ayer for his tireless and invaluable guidance, knowledge, and assistance in this research, particularly his positive influence, direction, and comments in the preparation of the study. We also extend our appreciation to all the Professional Surveyors and the Survey and Mapping Division especially the Photogrammetric section in the diverse ways they provided us with information we needed for the project. Finally, we appreciate the competitive edge of all final year Geomatic Engineering students of Kwame Nkrumah University of Science and Technology (KNUST) 2016 Batch. It has really been an honor to have studied and shared knowledge together.

Open Access This article is licensed under a Creative Commons Attribution 4.0 International License, which permits use, sharing, adaptation, distribution and reproduction in any medium or format, as long as you give appropriate credit to the original author(s) and the source, provide a link to the Creative Commons licence, and indicate if changes were made. The images or other third party material in this article are included in the article's Creative Commons licence, unless indicated otherwise in a credit line to the material. If material is not included in the article's Creative Commons licence and your intended use is not permitted by statutory regulation or exceeds the permitted use, you will need to obtain permission directly from the copyright holder. To view a copy of this licence, visit http://creativecommons.org/licenses/by/4.0/.

\section{Compliance with Ethical Standards}

The authors abided by the ethical standards of research.

Conflict of Interest The authors declare that they have no conflicts of interest.

Ethical Approval The field data collection (i.e., GPS observation, CORS data, and field interviews) was approved by the Survey and Mapping Division, Lands Commission. The authors used an approved oral informed consent for data collection.

Informed Consent The authors have given their informed consent to publish this article in the Journal of Geovisualization and Spatial Analysis.

Publisher's Note Springer Nature remains neutral with regard to jurisdictional claims in published maps and institutional affiliations. 